\title{
Lightweight self-cleaning trans-polyisoprene/multiwalled carbon nanotubes open-cell composite material: Its electromagnetic shielding performance
}

\author{
Y. Song, A. D. Phule, D. Wang, L. Ma, Z. X. Zhang* \\ Key Laboratory of Rubber-Plastics, Ministry of Education/Shandong Provincial Key Laboratory of Rubber-Plastics, \\ Qingdao University of Science and Technology, 266042 Qingdao, China
}

Received 12 January 2021; accepted in revised form 12 March 2021

\begin{abstract}
In this work, the open-cell material has been prepared by phase separation-sol-gel method, where trans-polyisoprene (TPI) is used as the raw material. Dichloromethane (DCM) has been used as a good solvent for TPI, and anhydrous ethanol as a poor solvent to achieve the phase separation. The formation of pores has been tuned and studied by adjusting the quantity of anhydrous ethanol. It has been determined that the best ratio of raw materials, good solvents and poor solvents is $1: 12: 1.5$. On this basis, the preparation process has been improved, and an open cell superhydrophobic composite material with good electromagnetic interference shielding effectiveness (EMI SE) and self-cleaning functions has been prepared. Multiwalled carbon nanotubes (MWCNTs) filler can form an effective 3D conductive network, and the material can be regarded as a disorderly accumulation of countless petal-like TPI flake particles with 1-10 $\mu \mathrm{m}$ size, forming interconnected and scattered cells through free overlap. The structure can make the composite material rough and form a multi-scale rough surface. The prepared TPI/MWCNTs open-cell composites (TMOCs) material has a low density of $0.27 \mathrm{~g} / \mathrm{cm}^{3}$ and a water contact angle (CA) of $153.5^{\circ}$ (in line with super-hydrophobic characteristics) and the EMI $S E$ can be up to $26 \mathrm{~dB}$ at a thickness of $5 \mathrm{~mm}$ and the corresponding specific EMI $S E$ has been achieved as high as $95.6 \mathrm{~dB} /\left(\mathrm{g} / \mathrm{cm}^{3}\right)$, which is far exceeding that of many carbon-based composite materials with similar density. This simple and inexpensive preparation process with excellent self-cleaning property and EMI SE of the materials can promote the practical application of such materials.
\end{abstract}

Keywords: polymer composites, trans-polyisoprene, superhydrophobic, self-cleaning, electromagnetic interference shielding effectiveness

\section{Introduction}

With the development of society and the progress of science and technology, modern electronic products with highly integrated circuits have developed rapidly. These electronic products benefit mankind, however they produce serious electromagnetic radiation, which have an adverse effects on equipment performance, human health and the surrounding environment. This scenario promotes the continuous improvement of electromagnetic interference (EMI) shielding materials and devices. In recent years, researchers have devoted themselves to explore novel and multifunctional EMI shielding material. Conductive polymer composites (CPCs) has the advantages of lightweight, good processability, tunable conductivity, corrosion resistance, etc., which has attracted great attention in electromagnetic interference shielding effectiveness (EMI SE) [1-6]. Many carbonbased materials, including carbon fibers, carbon nanofibers, carbon nanotubes and chemically derived graphene, have been used as conductive fillers for electromagnetic shielding composites due to their high electrical conductivity, light weight, and large aspect ratio [7-9]. Along with the high electromagnetic 
interference shielding performance, lightness is another important requirement for effective and practical EMI shielding applications, especially in the fields of aircraft, automobiles, and rapidly developing electronic products (such as portable electronic devices and wearable devices). To further reduce the weight of conductive polymer composites, the researchers have developed foam structures with the aid of expanding agents such as 2,2'-azoisobutyronitrile and super-critical/subcritical $\mathrm{CO}_{2}$ [10-13]. However, during the foaming process, the conductive network in the matrix will inevitably get disturbed. The EMI $S E$ after foaming is worse than that of the solid composite material with the same mass fraction of conductive filler [13]. Larger cells are easy to crack and embrittle the foam composite material. As a result, the specific EMI $S E$ (i.e. EMI $S E$ divided by the density) of most foam composites is only a few times greater than that of typical metals. On the other hand, apart from EMI $S E$, electronic equipment also puts forward new requirements, such as strong corrosion resistance and good self-cleaning. Building a superhydrophobic surface can make the self-cleaning material [14-16]. The preparation of superhydrophobic surface is mainly carried out by the following two schemes: one is to build a micronano-scale rough structure on the surface of the material; the other is to modify the rough structure with a low surface energy substance, such as depositing polydimethylsiloxane (PDMS) on the surface of the material by vapor deposition to prepare a superhydrophobic surface. Nowadays, many methods for preparing rough surfaces have been developed, including phase separation method, stencil printing method, electrospinning method, sol-gel method, template extrusion method, plasma etching method, stretching method and etching, etc. [17-20]. The water contact angle (CA) is often used as a criterion to decide the hydrophobicity of a solid surface. The CA greater than $150^{\circ}$ and the rolling angle less than $10^{\circ}$ are called superhydrophobic surfaces [21-23]. If micro-nano-level open-cell materials can be prepared, it can be widely used in self-cleaning and other fields.

Nowadays, trans-polyisoprene (TPI) has been practically applied in the fields of tyre modification, medical splints, orthopedic materials, golf covers, etc., and has achieved good economic benefits. In addition to the above-mentioned traditional fields, TPI can also be used in fields such as conductive heating fibers, light-to-heat conversion functional films [24], bio-antifouling materials [25] and foaming materials [26], which has also promoted the research and application of TPI, and has developed a new direction for the application of TPI and path.

In order to meet the needs of electronic equipment for material performance, to obtain the conductivity, self-cleaning and light weight of the material, and further expand the application range of TPI, in the present work, we have used TPI as the matrix, multiwalled carbon nanotubes (MWCNTs) as conductive fillers, and used a simple phase separation-solgel synthesis route to prepare superhydrophobic TPI/MWCNTs open-cell composites (TMOCs) with good EMI $S E$ and self-cleaning functions. During the phase separation of the material, the cell structure of the material and the conductive network are formed at the same time, and a material with a complete conductive network can be obtained. The material can be regarded as a disorderly accumulation of countless petal-like TPI flake particles with a size of only $1-10 \mu \mathrm{m}$. During the accumulation process, the MWCNTs attached to the surface of the TPI particles are connected to each other to form a 3D conductive network. At the same time, the disordered accumulation of particles formed a well-connected cell structure. A micro-nano-level dual structure of the material has maintained by controlling the amount of phase separation agent to adjust the size of the TPI particles. Such a rough structure finally makes the surface of the porous material super-hydrophobic. The obtained material has a large water CA $\left(152.7 \pm 2.3^{\circ}\right)$ and good EMI $S E$ which can reach $26.0 \mathrm{~dB}$ with the thickness of nearly $5 \mathrm{~mm}$. The density of the material is low and the material has excellent electromagnetic interference shielding performance, conductivity and super-hydrophobic self-cleaning properties. The application range of TPI has been expanded. The final prepared material is expected to be used in electronic devices that are severely affected by electromagnetic interference.

\section{Experimental section}

\subsection{Materials}

The TPI used was supplied by Qingdao Di pai New Material Co., Ltd. It has a molecular weight $30 \sim 50 \mathrm{~kg} / \mathrm{mol}$, melt flow index (MFI) $1.2 \mathrm{~g} / 10 \mathrm{~min}$ (ASTM D 1238) and density $0.85 \mathrm{~g} / \mathrm{cm}^{3}$. Dichloromethane (AR) was purchased from Tianjin Bei chen Founder Reagent Factory. Anhydrous ethanol (AR) 
has purchased from Tianjin Bo hua tong Chemical Product Sales Center. Multiwalled carbon nanotubes with diameter of $8-15 \mathrm{~nm}$, length of $30-50 \mu \mathrm{m}$ and density of $1.50 \mathrm{~g} / \mathrm{cm}^{3}$ were purchased from Chengdu Organic Chemicals, Chinese Academy of Science. All the chemicals were used as received without any further treatment.

\subsection{Preparation of super-hydrophobic open-cell TPI}

The sol-gel method and phase separation method were used to prepare open-cell TPI with micro-nanolevel cells. The preparation process is shown in Figure 1 . Set the water bath temperature to $36^{\circ} \mathrm{C}$ (constant temperature), dichloromethane was added in a three-necked flask, opened the stirring paddle, and added the appropriate amount of TPI particles; stirred for $3 \mathrm{~h}$ to fully dissolve the TPI, and then added an appropriate amount of absolute ethanol, as shown in Table 1. Stirred it for half an hour and poured it into a small beaker, micron-sized particles can be seen during the pouring process. Then poured anhydrous ethanol into the beaker and sealed the beaker with plastic wrap. The addition of absolute ethanol was used to replace the dichloromethane solvent in the mixture. Next, the beaker was placed in the freezer at a temperature of $6^{\circ} \mathrm{C}$. After $24 \mathrm{~h}$, the material was poured out and placed in a vacuum oven, and the temperature was raised and evacuated by a gradient heating method. Finally, the open-cell TPI was prepared. Each sample needs 6 grams of trans-polyisoprene particles, and the rest of the medicines can be taken according to the ratio in Table 2 . The product is a cylindrical with a diameter of $75 \mathrm{~mm}$ and a height of $5 \mathrm{~mm}$.

\subsection{Preparation of super-hydrophobic TPI/MWCNTs open-cell composites}

Based on the preparation of open-cell TPI, TOMCs with filling amounts of $0,5,10,15$ and $20 \mathrm{wt} \%$ were prepared, and they were abbreviated as TMOC0, TMOC5, TMOC10, TMOC15, TMOC20 respectively. The preparation process have shown in Figure 2. In short, before dissolving the TPI, the calculated

Table 1. The formulation of open- cell TPI.

\begin{tabular}{|c|c|c|c|c|c|c|c|c|c|}
\hline \multirow{2}{*}{ Material } & \multicolumn{9}{|c|}{ Experimental formula } \\
\hline & $1 \#$ & $2 \#$ & $3 \#$ & 4\# & $5 \#$ & $6 \#$ & $7 \#$ & $8 \#$ & 9\# \\
\hline TPI & 1 & 1 & 1 & 1 & 1 & 1 & 1 & 1 & 1 \\
\hline $\mathrm{CH}_{2} \mathrm{Cl}_{2}$ & 12 & 12 & 12 & 12 & 12 & 12 & 12 & 12 & 12 \\
\hline $\mathrm{C}_{2} \mathrm{H}_{5} \mathrm{OH}$ & 0.5 & 1.0 & 1.2 & 1.4 & 1.5 & 1.6 & 1.8 & 2.0 & 2.5 \\
\hline
\end{tabular}

Table 2. The formulation of TPI /MWCNTs open-cell composite material.

\begin{tabular}{|l|c|c|c|c|c|}
\hline \multicolumn{1}{|c|}{ Material } & \multicolumn{5}{c|}{ Experimental formula } \\
\hline & TMOC0 & TMOC5 & TMOC10 & TMOC15 & TMOC20 \\
\hline TPI & 1 & 1 & 1 & 1 & 1 \\
\hline $\mathrm{CH}_{2} \mathrm{Cl}_{2}$ & 12 & 12 & 12 & 12 & 12 \\
\hline $\mathrm{C}_{2} \mathrm{H}_{5} \mathrm{OH}$ & 1.5 & 1.5 & 1.5 & 1.5 & 1.5 \\
\hline MWCNTs & 0 & 0.053 & 0.111 & 0.176 & 0.25 \\
\hline
\end{tabular}

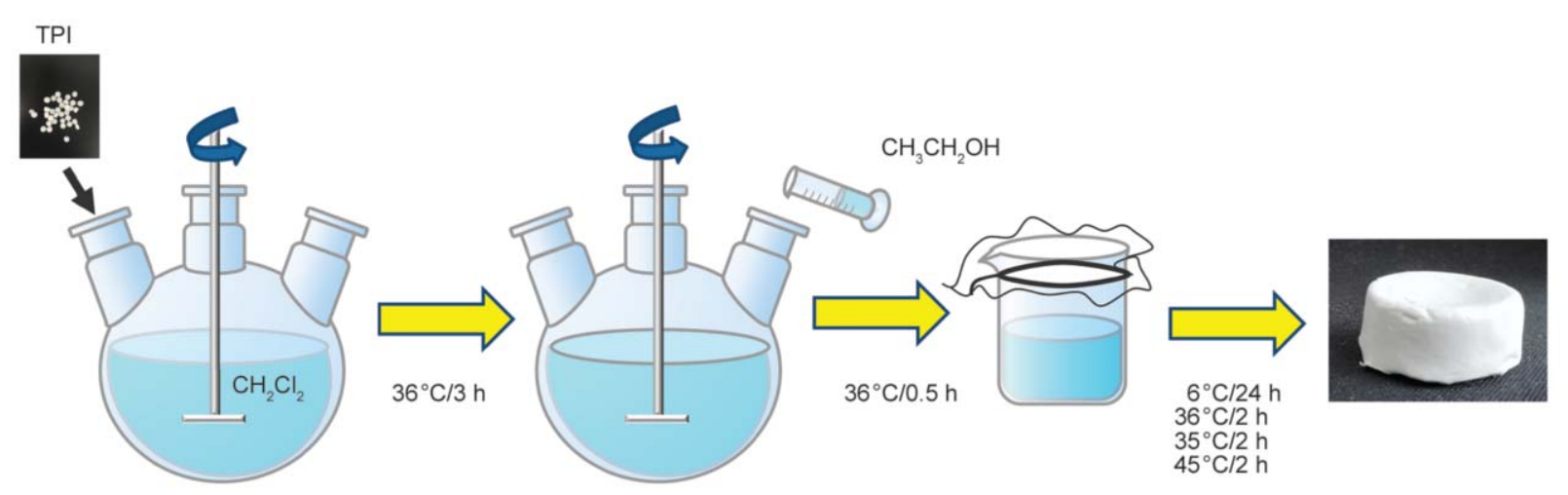

Figure 1. Schematic diagram of preparation of open-cell TPI. 


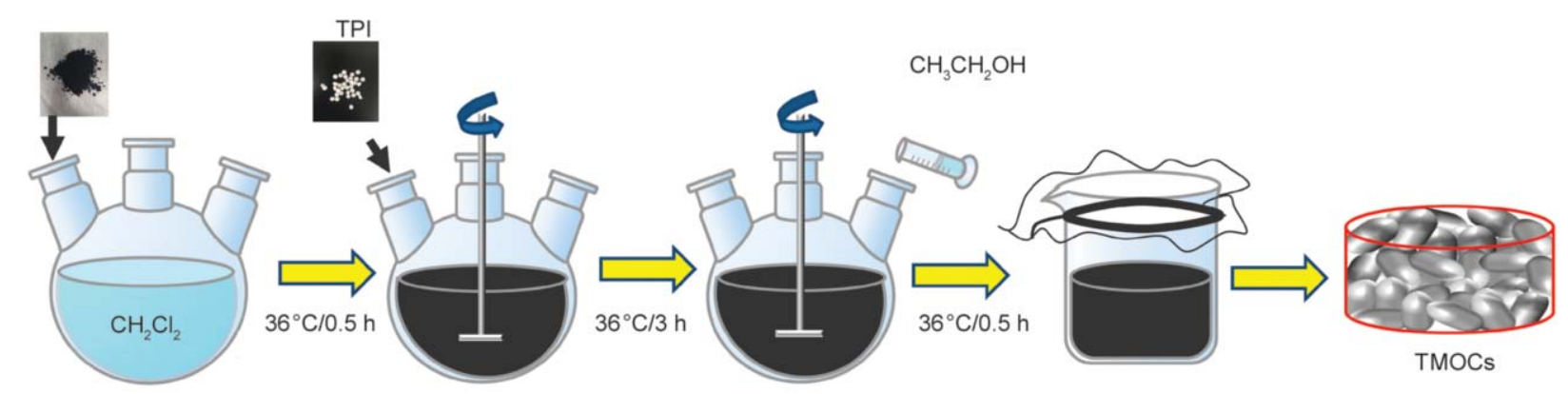

Figure 2. Schematic of preparation of TMOCs.

MWCNTs was added to the solvent dichloromethane (DCM), and then ultrasonically dispersed it for $1 \mathrm{~h}$ for further use. Set the water bath temperature to $36^{\circ} \mathrm{C}$ (constant temperature), DCM containing multiwalled carbon nanotubes was added in a three-necked flask, opened the stirring paddle, and added the appropriate amount of TPI particles; stirred for $3 \mathrm{~h}$ to fully dissolve the TPI, and then added an appropriate amount of absolute ethanol, as shown in Table 2. Stirred it for 30 minutes and poured it into a small beaker, micron-sized particles can be seen during the pouring process. Then poured anhydrous ethanol into the beaker and sealed the beaker with plastic wrap. The addition of absolute ethanol was used to replace the DCM solvent in the mixture. Next, the beaker was placed in the freezer at a temperature of $6^{\circ} \mathrm{C}$. After $24 \mathrm{~h}$, the material was poured out and placed in a vacuum oven, and the temperature was raised and evacuated by a gradient heating method. Finally, the open-cell TPI was prepared. Each sample needs 6 grams of trans-polyisoprene particles, and the rest of the medicines can be taken according to the ratio in Table 2 . The product is a cylinder with a diameter of $75 \mathrm{~mm}$ and a height of $5 \mathrm{~mm}$. The dosage of various materials have shown in Table 2.

\subsection{Characterization of super-hydrophobic open-cell TPI and TMOCs}

The microstructure of the open-cell TPI were investigated by a field emission scanning electron microscope (FESEM) (JSM-7500f, JEOL, Japan). First, we took the sample surface as the upper surface to cut a sample strip of $1 \mathrm{~mm} \times 1 \mathrm{~mm} \times 15 \mathrm{~mm}$, where we used a knife to take a sample block of $1 \mathrm{~mm} \times$ $1 \mathrm{~mm} \times 1 \mathrm{~mm}$, and then placed the sample surface up on the sample stage to observe the surface microstructure of the sample. We fixed the sample strip with pliers, and teared off a sample block of $1 \mathrm{~mm} \times 1 \mathrm{~mm} \times$ $1 \mathrm{~mm}$ with tweezers at the other end of the sample strip. The sample was placed on the sample stage with the tear side up to observe the microstructure of the tear surface of the sample; Put the sample strip in liquid nitrogen, freeze for 3 minutes, then the sample strip clamped with two pliers (with a spacing of about $1 \mathrm{~mm}$ ), the sample strip was braked; a knife was used to cut a $1 \mathrm{~mm} \times 1 \mathrm{~mm} \times 1 \mathrm{~mm}$ piece at a position with a brittle section. The sample block was placed on the sample stage with the fragile section of the sample facing up to observe the microstructure of the fragile section of the sample. The sample was sprayed with gold. The sample stage put into the scanning electron microscope to observe the clear interface structure of the product by adjusting the magnification and other parameters. When observing the 3D network structure, take the brittle section of the sample and observe it at a voltage of $3.0 \mathrm{kV}$. The static water contact angle (CA) of droplets on the open-cell material surfaces have been measured by using a contact angle measuring instrument (JC2000D, Shanghai Chen Zhong Digital Technology Limited, China). First, we cut out a $40 \mathrm{~mm} \times$ $10 \mathrm{~mm} \times 30 \mathrm{~mm}$ sample strip with the sample surface as the upper surface, and placed the sample surface upward on the sample table to test the static contact angle; fix the sample strip with pliers, and teared off a $10 \mathrm{~mm} \times 10 \mathrm{~mm} \times 30 \mathrm{~mm}$ sample block with another pliers on one end of the sample strip, and then placed the sample on the sample stage with the torn side up to test the static contact angle; then we put the sample strip in liquid nitrogen for a period of time, and then use two pliers (with a spacing of about $1 \mathrm{~mm}$ ) clamp the sample strip, break the sample strip, then we used a knife to cut a sample block of $10 \mathrm{~mm} \times$ $10 \mathrm{~mm} \times 30 \mathrm{~mm}$ at the position with the brittle section, and place the sample on the sample table with the brittle section facing up to test static contact angle. We moved the sample table to find a relatively flat position of the sample, and placed deionized water droplets $(5 \mu \mathrm{l})$ on the surface of the object to be measured, and 5 points were recorded at different 
positions for measurement, and the average value was taken. Each image file was measured by the angle measurement method. Finally, the water CA was obtained.

The measurement method of open-cell TPI's water CA is the same as that of TMOCs's water CA. The electrical performance of the samples was measured using a four-probe method [27] (4-Point Probes Resistivity Measurement System). The basic indicators of the four-point probe are as follows:

Spacing: $1.00 \pm 0.01 \mathrm{~mm}$;

Insulation resistance between pins: $\geq 1000 \mathrm{M} \Omega$;

Mechanical travel rate: $\leq 0.3 \%$;

Probe: Tungsten carbide, probe diameter $\varnothing 0.5 \mathrm{~mm}$; The pressure of the contact surface between the pins and the sample: $25.5 \sim 81.5 \mathrm{MPa}$.

Where $\varnothing$ is the probe diameter; the insulation resistance between the pins refers to the resistance between any two pins; the mechanical travel rate refers to the degree of deviation from the vertical direction when the probe contacts the sample.

The $S$ parameters $\left(S_{11}\right.$ and $\left.S_{21}\right)$ of the samples were recorded with vector network analyzer (R\&S ZNB20) using the wave-guide method in X-band (the sample dimension is $10.16 \mathrm{~mm} \times 22.86 \mathrm{~mm} \times 5 \mathrm{~mm}$ ), and the EMI $S E$ as well as $S E$ absorption, $S E$ reflection, Reflection coefficient $(R)$, Transmission coefficient $(T)$, and Absorption coefficient $(A)$, were determined based on the measured $S$ parameters as shown by Equations (1)-(4) [28-32]:

$$
\begin{aligned}
& R=\left|S_{11}\right|^{2}, T=\left|S_{22}\right|^{2} \\
& A=1-R-T \\
& S E_{\text {rel }}[\mathrm{dB}]=-10 \log (1-R), \\
& S E_{\text {abs }}[\mathrm{dB}]=-10 \log \left(\frac{T}{1-R}\right) \\
& S E_{\text {total }}[\mathrm{dB}]=10 \log \left(\frac{P_{\mathrm{I}}}{P_{\mathrm{T}}}\right)=S E_{\mathrm{rel}}+S E_{\text {abs }}
\end{aligned}
$$

where $P_{\mathrm{I}}$ is the incident power, and $P_{\mathrm{T}}$ is the transmitted power.

The density of the sample was estimated by geometric measurement of the cube sample used for electromagnetic shielding analysis [33].

The volume fraction in the bulk phase of MWCNTs is calculated by the Equation (5): $\varphi=\frac{\frac{m_{1}}{\rho_{1}}}{\frac{m_{2}}{\rho_{2}}+\frac{m_{1}}{\rho_{1}}}$

where $\varphi$ is the volume fraction in the bulk of MWCNTs, $m_{1}$ is the amount of MWCNTs added, $m_{2}$ is the amount of TPI, $\rho_{1}$ is the density of MWCNTs, and $\rho_{2}$ is the density of TPI.

The porosity of TMOC is obtained by the following Equation (6):

$P=\left(1-\frac{\rho}{\rho_{0}}\right) \cdot 100$

where $P$ is the porosity of TMOC, $\rho$ is the density of TOMC, $\rho_{0}$ is the density of the blend of TPI and MWCNTs (solid composites).

\section{Results and discussion}

\subsection{Super-hydrophobic open-cell TPI}

There are many methods for preparing open-celled materials, where different materials are suitable for different preparation methods. For TPI with high crystallinity and low melting point, phase separation-sol gel method is suitable to prepare open-cell materials $[34,35]$. TPI is easily dissolved by organic solvents such as alkanes, toluene, and xylene. Therefore, in this study, DCM was used as a good solvent for TPI, and absolute ethanol was used as a poor solvent. The pores formation was tuned and studied by controlling the amount of anhydrous ethanol. The effect of the amount of different phase separation agents on the micro-morphology of the material surface, brittle fracture surface and tear surface has been investigated by microstructural analysis (as shown in Figure 3) done by FESEM. Microstructural image of the brittle fracture sample in Figure $3 \mathrm{~b}$ shows the open-cell TPI with high pore structure which was prepared by the phase separation method. This material can be regarded as a disorderly accumulation of numerous TPI flake particles with a shape like a petal that is only $1-10 \mu \mathrm{m}$ in size. An interconnected and scattered pore structure is formed through free overlap. TPI particles are formed during the phase separation solution preparation. While TPI is completely dissolved in dichloromethane, the size of the TPI particles can be adjusted by controlling the amount of phase separation agent. Figure 3 a shows the surface micromorphology of the open-cell material. The size of the TPI flake particles and the size of the pores as well as the surface roughness of the material significantly 

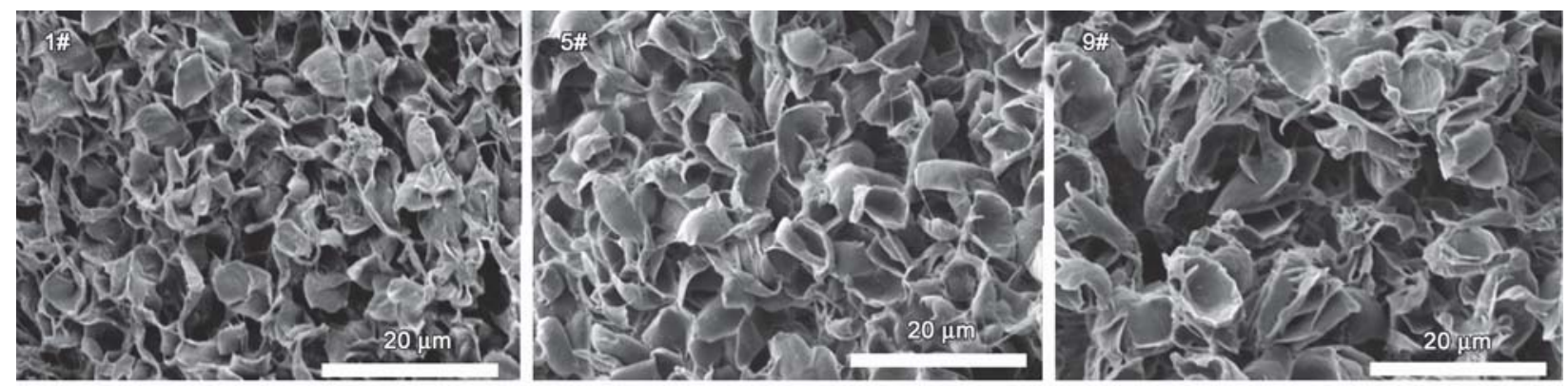

a)
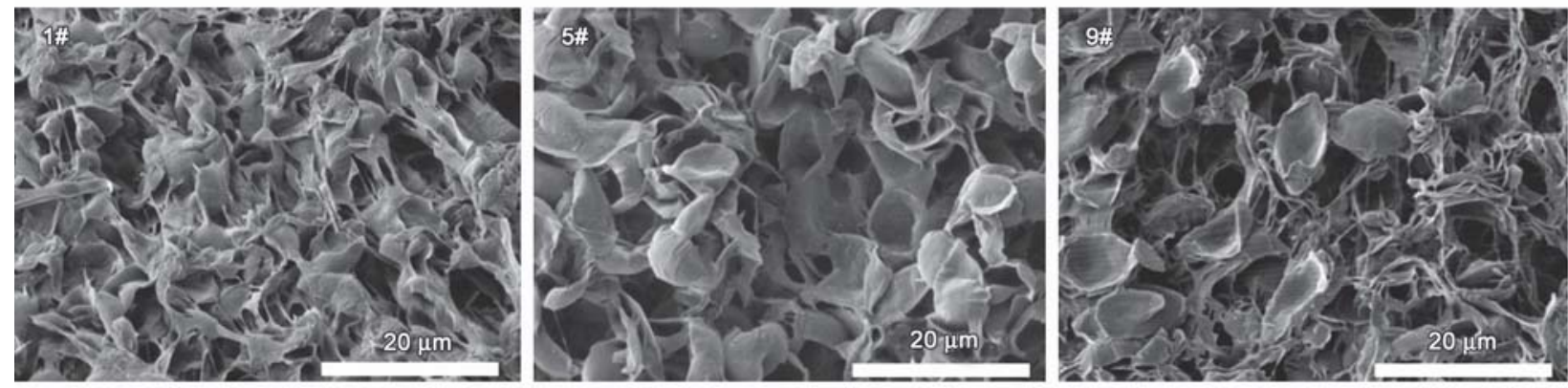

b)
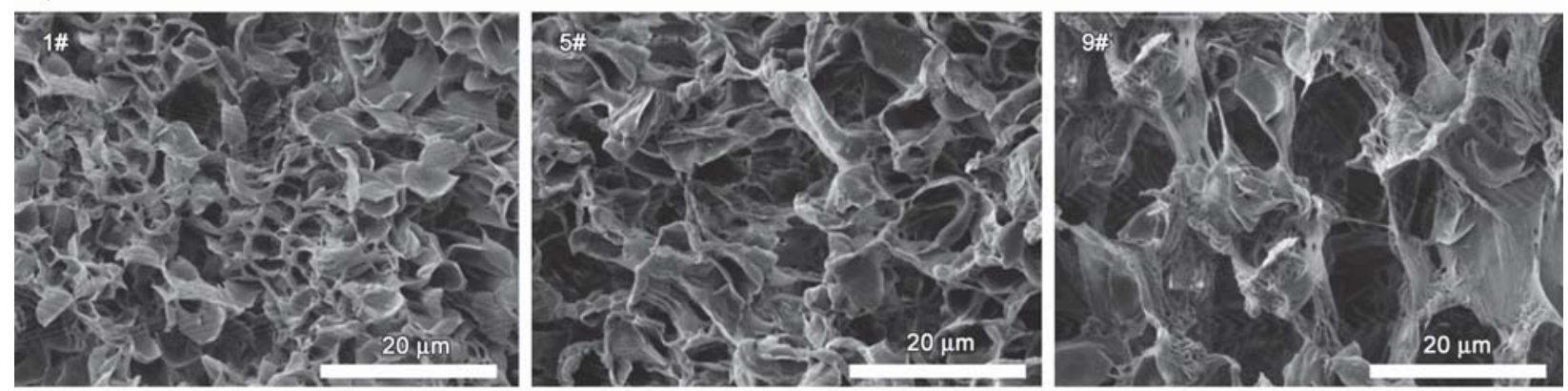

c)

Figure 3. SEM images of open-cell TPI. (a) Surface; (b) crisp section; (c) tearing surface;

1\#: TPI: $\mathrm{CH}_{2} \mathrm{Cl}_{2}: \mathrm{C}_{2} \mathrm{H}_{5} \mathrm{OH}=1: 12: 0.5 ;$ \#\#: TPI: $\mathrm{CH}_{2} \mathrm{Cl}_{2}: \mathrm{C}_{2} \mathrm{H}_{5} \mathrm{OH}=1: 12: 1.5 ; 9 \#:$ TPI: $\mathrm{CH}_{2} \mathrm{Cl}_{2}: \mathrm{C}_{2} \mathrm{H}_{5} \mathrm{OH}=1: 12: 2.5$.

increased with the increase of the absolute ethanol content. This is because during the free accumulation of TPI particles in the container, the excessively small particles are densely packed to form a smooth surface. The cell size and the surface roughness increases significantly with the increase of TPI particles. Figure 3c shows the micro-morphology of the tear surface of the material. Like the brittle section, it not only has a uniform pore structure $(1-10 \mu \mathrm{m})$, but also forms many uneven structures with a size of tens to hundreds of microns. This is because the interfacial bonding capacity of the porous structure formed by the natural accumulation of TPI particles is uneven. During the tearing process, the fracture occurs first in the weaker part of the adhesion, so a larger size is formed based on the micro-nano size secondary rough structure.

Figure 4 shows the effect of the amount of different phase separation agents on the water CA of the material surface and the tear surface. The water $\mathrm{CA}$ is an important parameter to confirm the hydrophobicity of a material. When the water CA between the surface of the material and water is greater than $150^{\circ}$, it referred as superhydrophobic. The water $\mathrm{CA}$ of the surface and the tearing surface of the $1 \#$ open-cell TPI are $108.5^{\circ}$ and $155^{\circ}$, respectively, and only the tearing surface had super hydrophobicity. With the increase of the amount of absolute ethanol, the water CA of the 5\# sample surface and the tear surface are $153.5^{\circ}$ and $156.7^{\circ}$. Both have superhydrophobic function. However, when the ratio is 1:12:2.5 (sample 9\#), the surface of the material lost its superhydrophobic ability, as shown in Figure 4. This is due to the formation of homogeneous system, as TPI is completely dissolved in DCM. Absolute ethanol promotes the phase separation of TPI, and TPI will gradually condense into small particles. As the content of absolute ethanol increases, the size of the small particles continues to increase. It states that, when the absolute ethanol content is small, the particle size is small, 


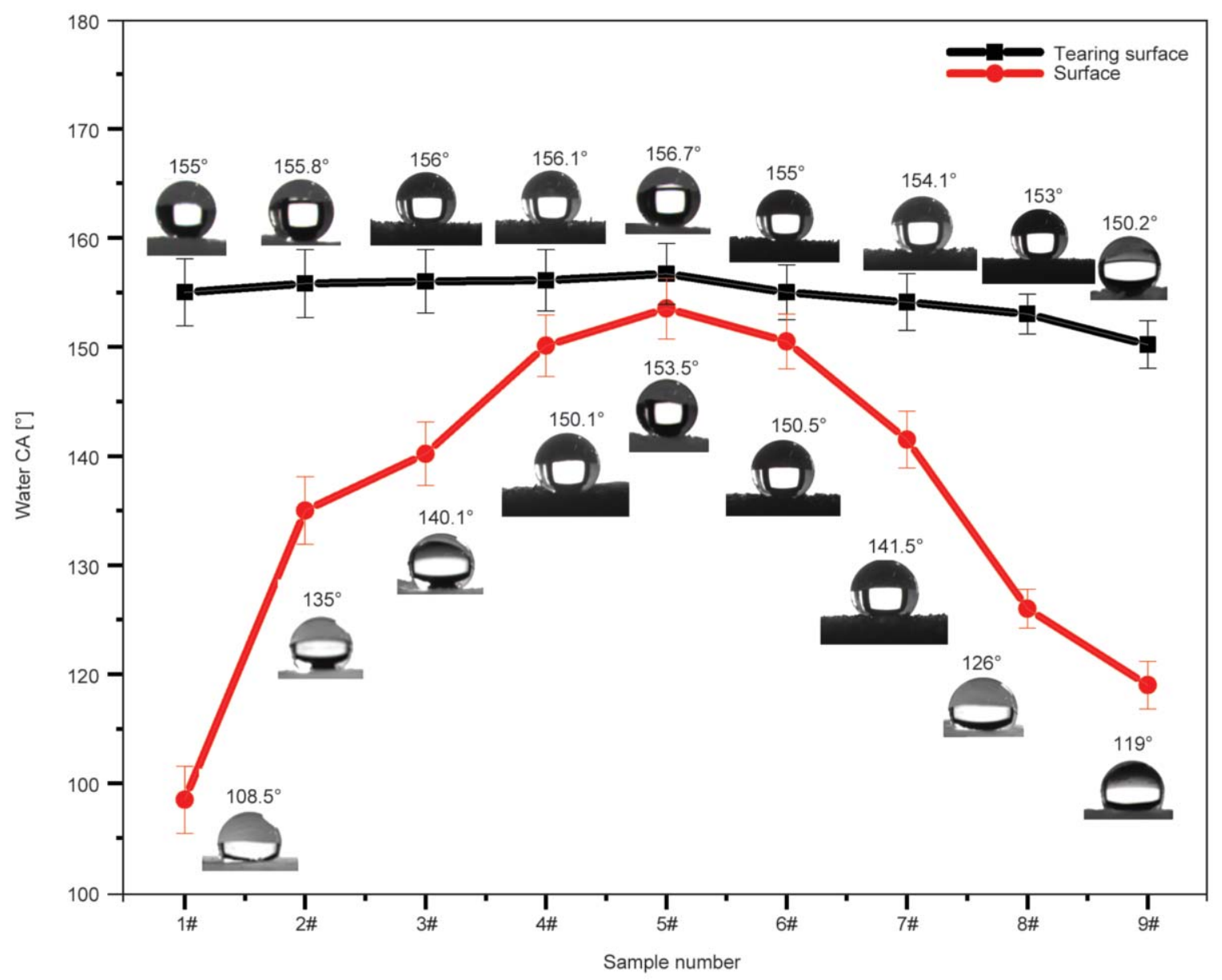

Figure 4. Water CA of open-cell TPI (1\#: TPI: $\mathrm{CH}_{2} \mathrm{Cl}_{2}: \mathrm{C}_{2} \mathrm{H}_{5} \mathrm{OH}=1: 12: 0.5 ; \quad 2 \#$ : TPI: $\mathrm{CH}_{2} \mathrm{Cl}_{2}: \mathrm{C}_{2} \mathrm{H}_{5} \mathrm{OH}=1: 12: 1.0$; 3\#: TPI: $\mathrm{CH}_{2} \mathrm{Cl}_{2}: \mathrm{C}_{2} \mathrm{H}_{5} \mathrm{OH}=1: 12: 1.2 ; 4 \#:$ TPI: $\mathrm{CH}_{2} \mathrm{Cl}_{2}: \mathrm{C}_{2} \mathrm{H}_{5} \mathrm{OH}=1: 12: 1.4 ; 5 \#:$ TPI: $\mathrm{CH}_{2} \mathrm{Cl}_{2}: \mathrm{C}_{2} \mathrm{H}_{5} \mathrm{OH}=1: 12: 1.5$; 6\#: TPI: $\mathrm{CH}_{2} \mathrm{Cl}_{2}: \mathrm{C}_{2} \mathrm{H}_{5} \mathrm{OH}=1: 12: 1.6 ; 7 \#$ : TPI: $\mathrm{CH}_{2} \mathrm{Cl}_{2}: \mathrm{C}_{2} \mathrm{H}_{5} \mathrm{OH}=1: 12: 1.8 ; 8 \#:$ TPI: $\mathrm{CH}_{2} \mathrm{Cl}_{2}: \mathrm{C}_{2} \mathrm{H}_{5} \mathrm{OH}=1: 12: 2.0$; 9\#: TPI: $\mathrm{CH}_{2} \mathrm{Cl}_{2}: \mathrm{C}_{2} \mathrm{H}_{5} \mathrm{OH}=1: 12: 2.5$ ) with surface and tearing surface.

and when the absolute ethanol content is high, the TPI particles are larger. The porous structure can be formed by the free accumulation of these particles, so it concludes that the size of the TPI particles prepared by formula (5) helps the accumulation to achieve the requirements of superhydrophobicity. The surface of porous materials also can be superhydrophobic. When the content of anhydrous ethanol is small, the resulting fine TPI particles are tightly packed and cannot reach the roughness required to be super-hydrophobic. When the mass fraction of anhydrous ethanol is high, TPI only forms large spheres with almost no small balls. The surface of the material is mainly formed by the accumulation of large balls along with the large pores, so the water CA is small, and the material did not showed the superhydrophobic function. However, the water contact angles of the tear surfaces of all the samples reached above $150^{\circ}$, indicating that the multi-stage rough structure shown in Figure 3 helps to form a superhydrophobic surface
[36]. An appropriate amount of phase separation agent concentration can form a certain roughness on the surface of the material, and the construction of the secondary micro-nano structure can greatly improve the hydrophobic function of the material.

\subsection{Super-hydrophobic TPI/MWCNTs open-cell composites}

\subsubsection{Morphology and dispersion of MWCNTs in TPI matrix}

The microstructure of TMOCs characterized by SEM, which has shown in Figure 5. The TMOCs prepared from TPI and MWCNTs presents uniform distribution of MWCNTs. When the loading of MWCNTs filler reaches a certain value (20 wt $\%$ ), MWCNTs are closely attached to the surface of TPI particles and connected to each other to form a 3D network structure, which helps to improve conductivity of the material (discussed in the next section). 

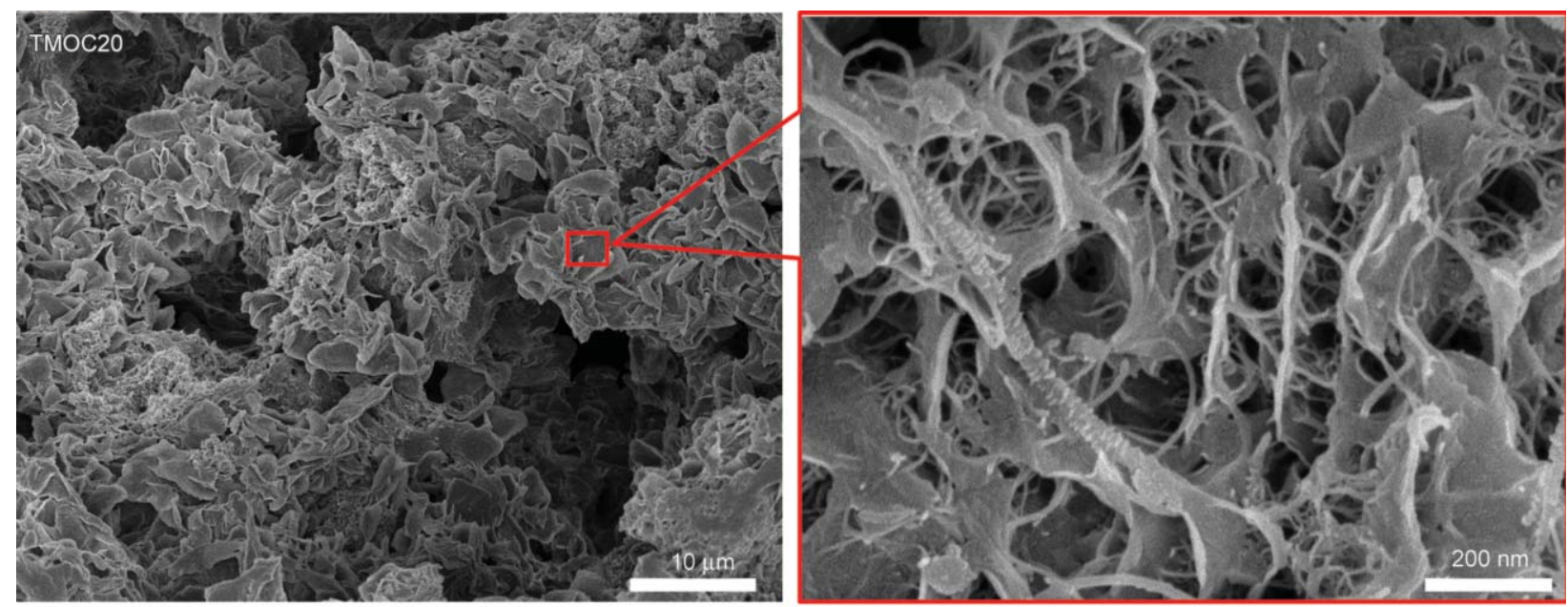

Figure 5. Representative SEM micrographs of brittle section of TMOCs; i.e. TMOC20 with close view showing 3D network structure.

\subsubsection{DC conductivity of the TMOCs}

Based on the importance of electromagnetic shielding, we used the four-probe method to test the electrical performance of the TMOCs very firstly. As showed in Figure 6, the DC conductivity of the TMOC material increased with the filler content, i.e. from $1 \cdot 10^{-14} \mathrm{~S} / \mathrm{m}$ for open cell TPI to $2 \mathrm{~S} / \mathrm{m}$ for the TMOC15 and reached to the highest value of $3.28 \mathrm{~S} / \mathrm{m}$ for TMOC20, which is more than 3 orders of the magnitude greater than the conventional CNTs and CDG (chemically derived graphene) based polymer composites. And this value far exceeds the target value of conductivity of commercial EMI $S E$ mate$\operatorname{rial}(1 \mathrm{~S} / \mathrm{m})$. This should be attributed to the fact that the filler forms an effective conductive network structure in the polymer matrix.

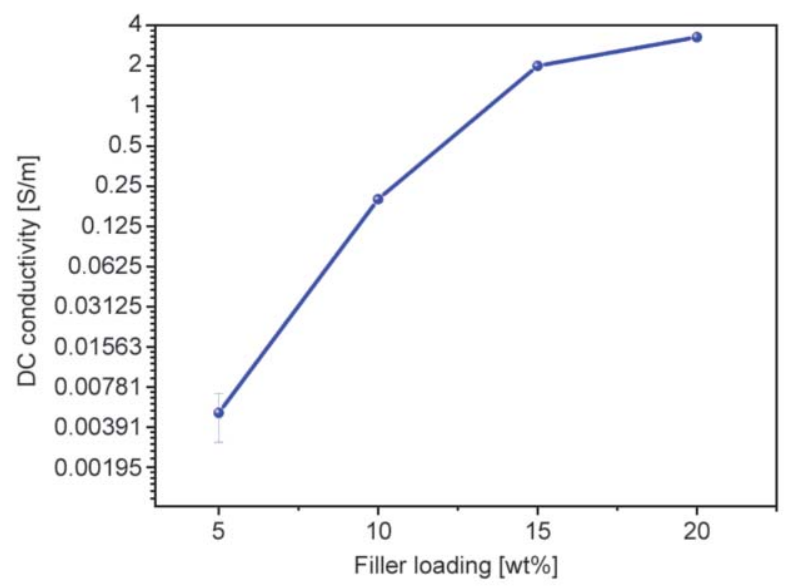

Figure 6. DC conductivity of the TMOCs with different filler loading [wt\%]; 0, 5, 10, 15, 20.

\subsubsection{EMI $S E$ of TMOCs}

Figure 7a shows the EMI $S E$ values of the TMOCs recorded in the frequency range of 8.2 to $12.4 \mathrm{GHz}$. At the same frequency range, the $S E$ gradually increases with the increased MWCNTs filler load. The EMI $S E$ value of the TMOCs with a conductivity of $2 \mathrm{~S} / \mathrm{m}$ (15 wt \% MWCNTs) (9.1 Vol\% MWCNTs) in the $\mathrm{X}$ band is nearly $10 \mathrm{~dB}$, which is still far behind the EMI $S E$ value required in commercial application (i.e. $20 \mathrm{~dB}$ ). However, the EMI $S E$ value of the TMOC20 with conductivity of $3.28 \mathrm{~S} / \mathrm{m}$ increases to $26 \mathrm{~dB}$ exceeding the target value of $20 \mathrm{~dB}$ which is required criterion for the commercial application. In addition as first proposed by Papageorgiou et al. [7], the specific EMI SE (i.e. EMI $S E$ divided by density) is considered more suitable to evaluate the EMI shielding abilities of low density porous material. The EMI $S E$ of TMOC15 is 8.1 to $10.2 \mathrm{~dB}$ and the corresponding average EMI $S E$ can reach about $40 \mathrm{~dB} /\left(\mathrm{g} / \mathrm{cm}^{3}\right)$ in the measurement frequency range. This value is higher than the typical metals (i.e. $\left.10 \mathrm{~dB} /\left(\mathrm{g} / \mathrm{cm}^{3}\right)\right)$. The EMI $S E$ value per unit density of TMOC20 can reach $\sim 95.6 \mathrm{~dB} /\left(\mathrm{g} / \mathrm{cm}^{3}\right)$ which exceeds many EMI shielding materials based on the electrical fillers (see Table 3). However, it can be seen from Table 3 that the EMI $S E$ value per unit thickness of the sample is not high, only $5.2 \mathrm{~dB} / \mathrm{mm}$. But, the outstanding SSE value and additional superhydrophobic properties (water CA $153.2^{\circ}$ ) make the TMOCs material in the actual EMI shielding still have strong competitiveness. We have analyzed the 
EMI SE mechanism of TMOCs. It is well known that when the microwave incidents on electromagnetic shield, phenomena such as absorption, transmission, and reflection occurs. The increase in filler loading increases the amount of mobile charge carrier in the sample [14], thereby enhancing the $S E$ absorption and

Table 3. Comparison of reported values of EMI SE, SSE for different composites measured in the X-band frequency range.

\begin{tabular}{|l|c|c|c|c|c|}
\hline \multicolumn{1}{|c|}{ Material } & $\begin{array}{c}\text { Filler content } \\
{[\mathbf{w t} \mathbf{0}]}\end{array}$ & $\begin{array}{c}\boldsymbol{S E} \text { per unit thickness } \\
{[\mathbf{B} / \mathbf{m m}]}\end{array}$ & $\begin{array}{c}\boldsymbol{S E} \\
{[\mathbf{d B}]}\end{array}$ & $\begin{array}{c}\boldsymbol{S S E} \\
{\left[\mathbf{d B} /\left(\mathbf{g} / \mathbf{c m}^{\mathbf{3}}\right)\right]}\end{array}$ & Ref. \\
\hline TPI-MWCNTs & 20.0 & $5.2 \pm 0.6$ & $26.0 \pm 3$ & $95.6 \pm 11$ & This work \\
\hline PEI-graphene & 10.0 & 5.7 & 13.0 & 44.0 & {$[38]$} \\
\hline PS-CNTs & 7.0 & $\mathrm{~N} / \mathrm{A}$ & 19.0 & 33.1 & {$[10]$} \\
\hline PMMA-graphene & 5.0 & 7.9 & 19.0 & 24.0 & {$[39]$} \\
\hline PDMS-graphene & 0.8 & 20.0 & 20.0 & 333.0 & {$[40]$} \\
\hline Cellulose-CNTs & 10.0 & 8.4 & 21.0 & 219.0 & {$[41]$} \\
\hline PLLA-MWCNT & 10.0 & 9.2 & 23.0 & 77.0 & {$[42]$} \\
\hline PS-graphene & 30.0 & 11.6 & 29.0 & 64.4 & {$[43]$} \\
\hline PVDF-graphene & 7.0 & N/A & 28.0 & N/A & {$[11]$} \\
\hline ALC & N/A & 5.1 & 51.0 & 455.4 & {$[44]$} \\
\hline GN-CNF & N/A & 108.0 & 27.0 & 270.0 & {$[45]$} \\
\hline
\end{tabular}

N/A: not available.
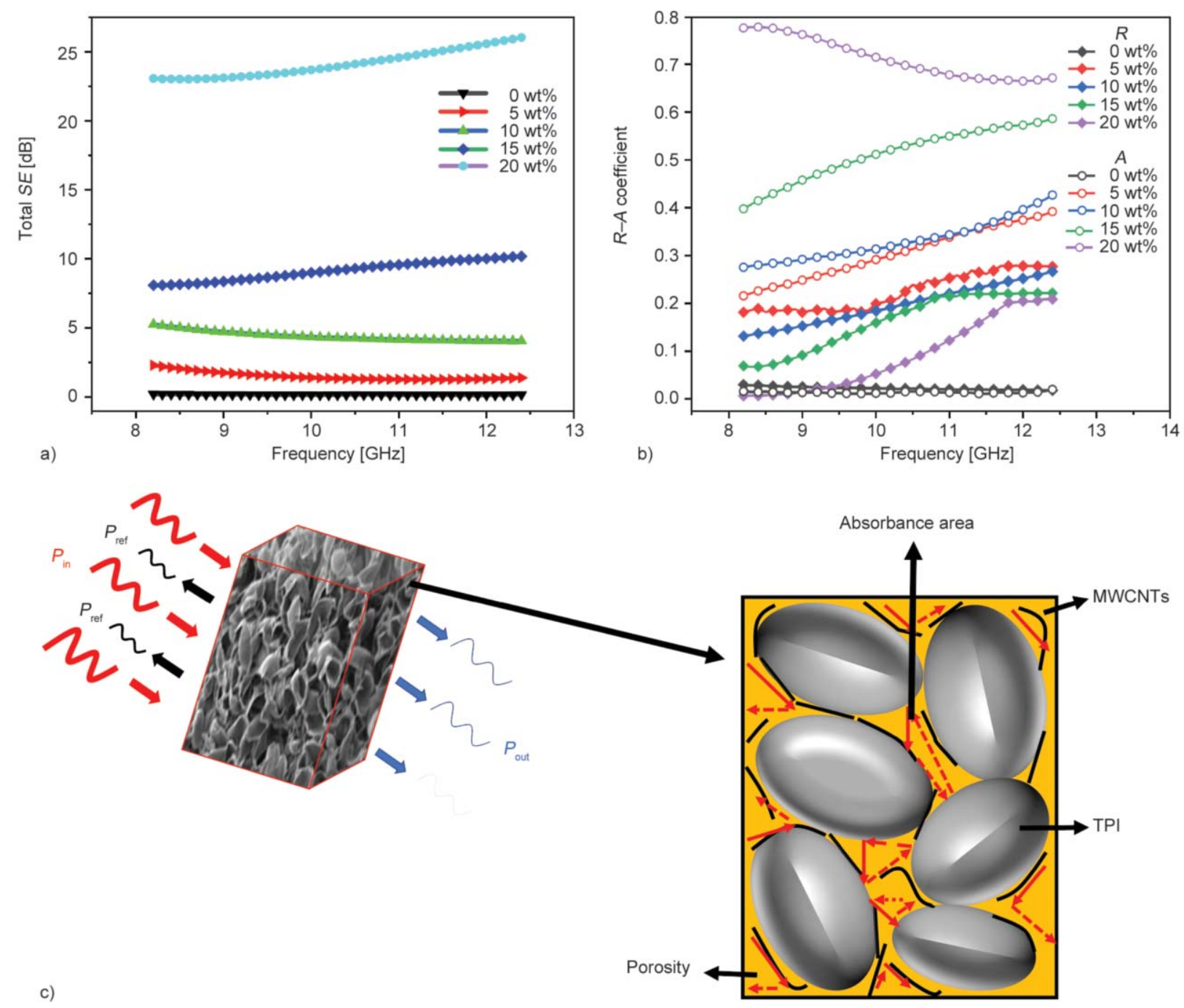

Figure 7. (a) Plots of total $S E$ for the TMOCs with different filler loading [wt\%]; 0, 5, 10, 15, 20 in X-band; (b) $R-A$ coefficient of the TMOCs; (c) Schematic description of electromagnetic microwave dissipation in the TMOCs. 
$S E$ reflection. The reason for the reflection is the impedance mismatch between the sample and the air interface, and the absorption is mainly due to the large number of unit cell matrix interfaces in the porous microstructure leading to conductive dissipation and multiple times reflection $[4,7,18,20,22$, 28], and interface polarization caused by more interfaces [21, 29-31]. A large number of micro-nanoscale particles attached to MWCNTs are formed during the phase separation process of TMOCs samples. Therefore, it is speculated that this type of TMOCs has a shielding mechanism based on absorption [37]. The schematic diagram of electromagnetic microwave dissipation of TMOCs has shown in Figure 7c. Due to highly open perforated structure, incident electromagnetic waves can easily enter the perforated material, which also shows that TMOCs has a shielding mechanism based on absorption. In order to explore the shielding mechanism of TMOCs further, the corresponding $R-A$ coefficient was calculated according to the $S$ parameters of each sample. For TMOCs samples with different filler loading, the $R$ coefficient is around 0.08 to 0.25 , which is almost less than the $A$ coefficient of 0.3 to 0.78 (see Figure $7 \mathrm{~b}$ ). This further confirms that this type of TMOCs has the shielding mechanism based on the absorption. Therefore, such kind of material is most effective to solve the problem of secondary magnetic pollution caused by electromagnetic wave reflection.

\subsubsection{Lightweight, superhydrophobic, and self-cleaning properties of TMOCs}

After calculation, the mass fraction and volume fraction of MWCNTs and the porosity of sample are shown in Table 4. As shown in Figure 8, the density of TMOCs with different filler loading of $5,10,15$, and $20 \mathrm{wt} \%$ was estimated in the range of 0.18 $0.27 \mathrm{~g} / \mathrm{cm}^{3}$, indicating the weight reduction of $72 \sim$ $79 \%$ in comparison with solid composites with density of $0.86 \sim 0.97 \mathrm{~g} / \mathrm{cm}^{3}$. Lightweight material promotes the application of materials in the field of electromagnetic interference shielding. A large number of studies have proved that materials with high hydrophobicity with water contact angles $>150^{\circ}$, shows high water repellency and good self-cleaning properties [37]. The water CA of the surface and the tear surface of the TMOCs are all above $150^{\circ}$ (as shown in Figure 9). As shown in Figure 5, in the TMOC20 sample with high EMI SE, an impact of a multi-level rough structure formed by the disorderly
Table 4. The mass fraction $(\Omega)$ and volume fraction $(\Phi)$ of MWCNTs and the porosity $(P)$ of sample.

\begin{tabular}{|l|c|c|c|c|c|c|}
\hline \multicolumn{2}{|c|}{ Sample } & TMOC0 & TMOC5 & TMOC10 & TMOC15 & TMOC20 \\
\hline$\Omega$ & {$[\%]$} & 0 & 5 & 10 & 15 & 20 \\
\hline$\Phi$ & {$[\%]$} & 0 & 2.9 & 6.0 & 9.1 & 12.5 \\
\hline$P$ & {$[\%]$} & 79 & 77 & 74 & 73 & 72 \\
\hline
\end{tabular}

$\Omega$ represents the mass fraction of MWCNTs $\Phi$ represents the volume fraction of MWCNTs

$P$ represents the porosity of the sample.

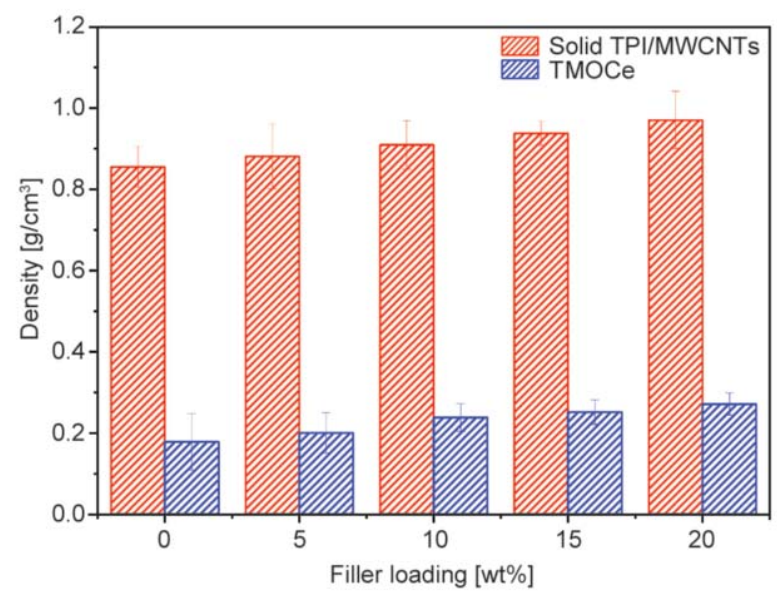

Figure 8. Densities of the TMOCs (with filler loading [wt\%]; 0, 5, 10, 15, 20) and solid TPI/MWCNTs.

accumulation of many TPI flake particles can still be observed, which greatly improves the hydrophobic function of the material. The filler loading does not affect much the hydrophobicity of the TMOCs, even at higher filler loading i.e. $20 \mathrm{wt} \%$ the water CA is $152^{\circ}$ and $153.4^{\circ}$ in TMOC material surface and teared surface respectively. The results show that the TMOCs have good water repellency and self-cleaning properties. The prepared lightweight material with superhydrophobicity can open the wide scope in practical applications.

\section{Conclusions}

We have used simple and cost-effective methods (solgel and phase separation method) to prepare lightweight TMOCs with excellent super hydrophobicity, electrical conductivity, and EMI SE. The prepared TMOCs material has a low density of $0.27 \mathrm{~g} / \mathrm{cm}^{3}$ and multi-scale rough surface morphology along with a water $\mathrm{CA}$ of $153.5^{\circ}$. The open-cell composite material TMOC20 with MWCNTs filler (20 wt $\%$ MWCNTs, $5.0 \mathrm{~mm}$ thickness) can form an effective $3 \mathrm{D}$ conductive network having a conductivity of $3.28 \mathrm{~S} / \mathrm{m}$. TMOC20 showed EMI $S E$ value of about $26.0 \mathrm{~dB}$ (in the frequency range of $8.2 \sim 12.4 \mathrm{GHz}$ ). 


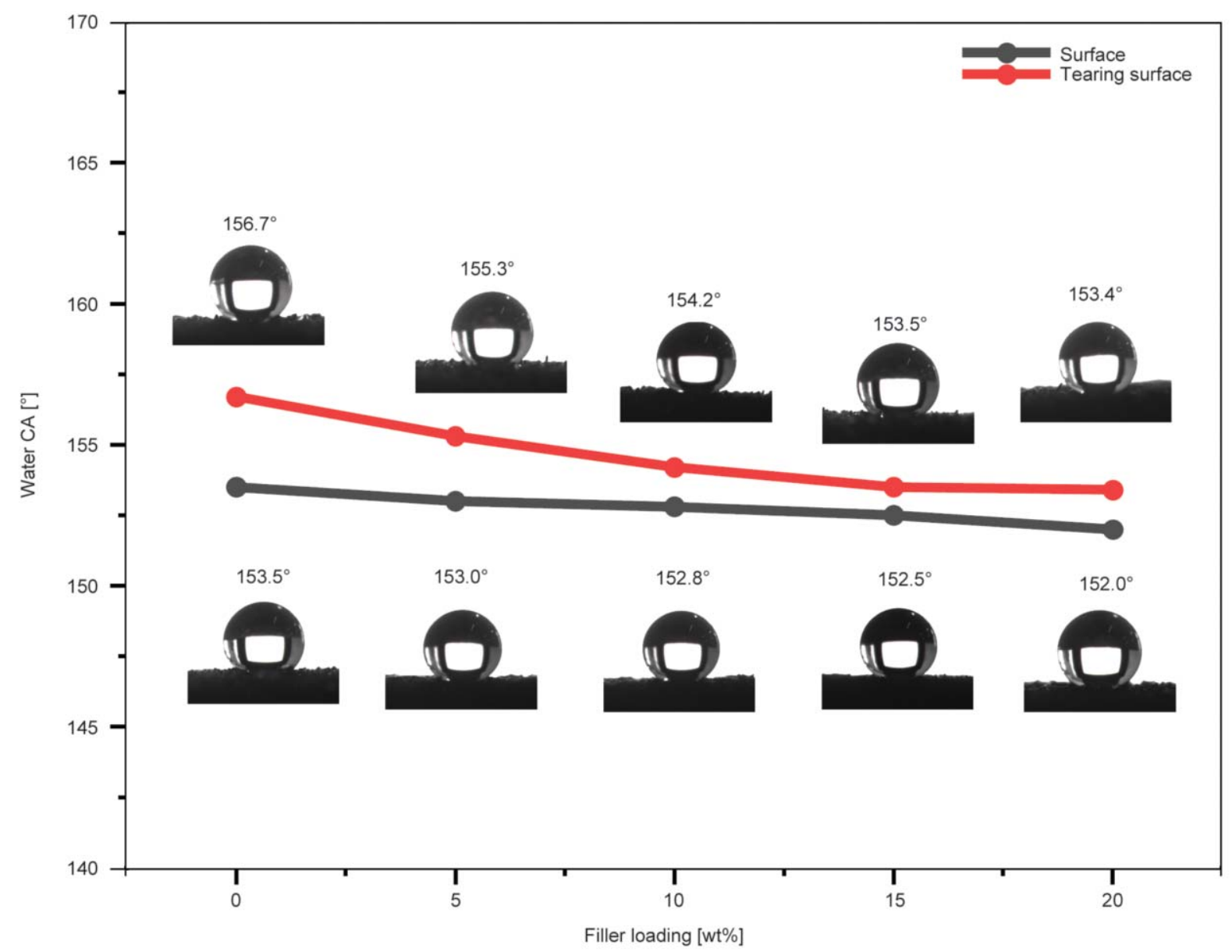

Figure 9. Water CA of the TMOCs (with filler loading [wt\%]; 0, 5, 10, 15, 20) with surface and tearing surface.

The corresponding specific EMI $S E$ has achieved as high as $95.6 \mathrm{~dB} /\left(\mathrm{g} / \mathrm{cm}^{3}\right)$, which is far exceeding that of metals and many carbon-based composite materials with similar density. Simple preparation methods and excellent performance will promote the commercialization of such materials in practical applications like electronic devices that are severely affected by electromagnetic interference.

\section{References}

[1] Chen Y., Zhang H-B., Yang Y., Wang M., Cao A., Yu Z-Z.: High-performance epoxy nanocomposites reinforced with three-dimensional carbon nanotube sponge for electromagnetic interference shielding. Advanced Functional Materials, 26, 447-455 (2016). https://doi.org/10.1002/adfm.201503782

[2] Li Y., Li C., Zhao S., Cui J., Zhang G., Gao A., Yan Y.: Facile fabrication of highly conductive and robust three-dimensional graphene/silver nanowires bicontinuous skeletons for electromagnetic interference shielding silicone rubber nanocomposites. Composites Part A: Applied Science and Manufacturing, 119, 101-110 (2019).

https://doi.org/10.1016/j.compositesa.2019.01.025
[3] Shen Q., Li H., Li L., Li L., Li W., Song Q.: Simultaneously improving the mechanical strength and electromagnetic interference shielding of carbon/carbon composites by electrophoretic deposition of $\mathrm{SiC}$ nanowires. Journal of Materials Chemistry C, 6, 5888-5899 (2018). https://doi.org/10.1039/C8TC01313F

[4] Yan D-X., Pang H., Li B., Vajtai R., Xu L., Ren P-G., Wang J-H., Li Z-M.: Structured reduced graphene oxide/polymer composites for ultra-efficient electromagnetic interference shielding. Advanced Functional Materials, 25, 559-566 (2015).

https://doi.org/10.1002/adfm.201403809

[5] Song W-L., Cao M-S., Lu M-M., Bi S., Wang C-Y., Liu J., Yuan J., Fan L-Z.: Flexible graphene/polymer composite films in sandwich structures for effective electromagnetic interference shielding. Carbon, 66, 67-76 (2014).

https://doi.org/10.1016/j.carbon.2013.08.043

[6] Wang H., Zheng K., Zhang X., Ding X., Zhang Z., Bao C., Guo L., Chen L., Tian X.: 3D network porous polymeric composites with outstanding electromagnetic interference shielding. Composites Science and Technology, 125, 22-29 (2016).

https://doi.org/10.1016/j.compscitech.2016.01.007 
[7] Papageorgiou D. G., Kinloch I. A., Young R. J.: Mechanical properties of graphene and graphene-based nanocomposites. Progress in Materials Science, 90, 75127 (2017).

https://doi.org/10.1016/j.pmatsci.2017.07.004

[8] Al-Saleh M. H., Sundararaj U.: A review of vapor grown carbon nanofiber/polymer conductive composites. Carbon, 47, 2-22 (2009).

https://doi.org/10.1016/j.carbon.2008.09.039

[9] Moniruzzaman M., Winey K. I.: Polymer nanocomposites containing carbon nanotubes. Macromolecules, 39, 5194-5205 (2006). https://doi.org/10.1021/ma060733p

[10] Yang Y., Gupta M. C., Dudley K. L., Lawrence R. W.: Novel carbon nanotube-polystyrene foam composites for electromagnetic interference shielding. Nano Letters, 5, 2131-2134 (2005).

https://doi.org/10.1021/n1051375r

[11] Eswaraiah V., Sankaranarayanan V., Ramaprabhu S.: Functionalized graphene-PVDF foam composites for EMI shielding. Macromolecular Materials and Engineering, 296, 894-898 (2011).

https://doi.org/10.1002/mame.201100035

[12] Fletcher A., Gupta M. C., Dudley K. L., Vedeler E.: Elastomer foam nanocomposites for electromagnetic dissipation and shielding applications. Composites Engineering and Technology, 70, 953-958 (2010). https://doi.org/10.1016/j.compscitech.2010.02.011

[13] Thomassin J-M., Pagnoulle C., Bednarz L., Huynen I., Jerome R., Detrembleur C.: Foams of polycaprolactone/MWNT nanocomposites for efficient EMI reduction. Journal of Materials Chemistry, 18, 792-796 (2008). https://doi.org/10.1039/B709864B

[14] Tian D., Song Y., Jiang L.: Patterning of controllable surface wettability for printing techniques. Chemical Society Review, 42, 5184-5209 (2013). https://doi.org/10.1039/C3CS35501B

[15] Li S., Huang J., Chen Z., Chen G., Lai Y.: A review on special wettability textiles: Theoretical models, fabrication technologies and multifunctional applications. Journal of Materials Chemistry A, 5, 31-55 (2017). https://doi.org/10.1039/C6TA07984A

[16] Hui L., Huang J., Chen Z., Chen G., Zhang K-Q., Al-Deyab S., Lai Y.: Robust translucent superhydrophobic PDMS/PMMA film by facile one-step spray for self-cleaning and efficient emulsion separation. Chemistry Engineering Journal, 330, 26-35 (2017). https://doi.org/10.1016/j.cej.2017.07.114

[17] Cheng Z., Du M., Lai H., Zhang N., Sun K.: From petal effect to lotus effect: A facile solution immersion process for the fabrication of super-hydrophobic surfaces with controlled adhesion. Nanoscale, 5, 2776-2783 (2013). https://doi.org/10.1039/C3NR34256E
[18] Wang S., Liu Q., Zhang Y., Wang S., Li Y., Yang Q., Song Y.: Preparation of a multifunctional material with superhydrophobicity, superparamagnetism, mechanical stability and acids-bases resistance by electrospinning. Applied Surface Science, 279, 150-158 (2013). https://doi.org/10.1016/j.apsusc.2013.04.060

[19] Li J., Kang R., Zhang Y., Li M., She H., Zha F., Lei Z.: Facile fabrication of superhydrophobic meshes with different water adhesion and their influence on oil/water separation. RSC Advances, 6, 90824-90830 (2016). https://doi.org/10.1039/C6RA17153B

[20] Wen G., Guo Z., Liu W.: Biomimetic polymeric superhydrophobic surfaces and nanostructures: From fabrication to applications. Nanoscale, 9, 3338-3366 (2017). https://doi.org/10.1039/C7NR00096K

[21] Anjum A. S., Ali M., Sun K. C., Riaz R., Jeong S. H.: Self-assembled nanomanipulation of silica nanoparticles enable mechanochemically robust super hydrophobic and oleophilic textile. Journal of Colloid Interface Science, 563, 62-73 (2020). https://doi.org/10.1016/j.jcis.2019.12.056

[22] Xu C-L., Wang Y-Z.: Durability, anti-corrosion and self-clean in air/oil of a transparent superhydrophobic polyimide film. Applied Materials Today, 10, 18-23 (2018). https://doi.org/10.1016/j.apmt.2017.11.008

[23] Lv Z., Yu S., Song K., Zhou X., Yin X.: Fabrication of a leaf-like superhydrophobic $\mathrm{CuO}$ coating on 6061Al with good self-cleaning, mechanical and chemical stability. Ceramic International, 46, 14872-14883 (2020). https://doi.org/10.1016/j.ceramint.2020.03.013

[24] Li R., Wang Z., Han P., He Y., Zhang X., Wang Y.: Refreshing rubbers as customized photothermal conversion materials through post-darkening modeling production. Chemistry A European Journal, 23, 1788917893 (2017). https://doi.org/10.1002/chem.201704715

[25] Li R., Lian X., Wang Z., Wang Y.: Radical cation initiated surface polymerization on photothermal rubber for smart antifouling coatings. Chemistry A European Journal, 25, 183-188 (2019).

https://doi.org/10.1002/chem.201804526

[26] Xia L., Gao H., Geng J.: Facile fabrication of foamed natural Eucommia ulmoides gum composites with heattriggered shape memory behavior. Polymer Composites, 40, 3075-3083 (2019). https://doi.org/10.1002/pc.25152

[27] Ma X., Shen B., Zhang L., Liu Y., Zhai W., Zheng W.: Porous superhydrophobic polymer/carbon composites for lightweight and self-cleaning EMI shielding application. Composites Science and Technology, 158, 8693 (2018).

https://doi.org/10.1016/j.compscitech.2018.02.006

[28] Al-Saleh M. H., Saadeh W. H., Sundararaj U.: EMI shielding effectiveness of carbon based nanostructured polymeric materials: A comparative study. Carbon, 60, 146-156 (2013). https://doi.org/10.1016/j.carbon.2013.04.008 
[29] Maiti S., Shrivastava N. K., Suin S., Khatua B. B.: Polystyrene/MWCNT/graphite nanoplate nanocomposites: Efficient electromagnetic interference shielding material through graphite nanoplate-MWCNT-graphite nanoplate networking. ACS Applied Materials Interfaces, 5, 4712-4724 (2013).

https://doi.org/10.1021/am400658h

[30] Shen B., Li Y., Yi D., Zhai W., Wei X., Zheng W.: Microcellular graphene foam for improved broadband electromagnetic interference shielding. Carbon, 102, 154-160 (2016). https://doi.org/10.1016/j.carbon.2016.02.040

[31] Song W-L., Fan L-Z., Cao M-S., Lu M-M., Wang C-Y., Wang J., Chen T-T., Li Y., Hou Z-L., Liu J., Sun Y-P.: Facile fabrication of ultrathin graphene papers for effective electromagnetic shielding. Journal of Material Chemistry C, 2, 5057-5064 (2014). https://doi.org/10.1039/C4TC00517A

[32] Song W-L., Guan X-T., Fan L-Z., Cao W-Q., Wang C-Y., Cao M-S.: Tuning three-dimensional textures with graphene aerogels for ultra-light flexible graphene/texture composites of effective electromagnetic shielding. Carbon, 93, 151-160 (2015).

https://doi.org/10.1016/j.carbon.2015.05.033

[33] Lopez-Gonzalez E., Saiz-Arroyo C., Rodriguez-Perez M. A.: Low-density open-cell flexible polyolefin foams as efficient materials for oil absorption: Influence of tortuosity on oil absorption. International Journal of Environmental Science and Technology, 17, 1663-1674 (2019).

https://doi.org/10.1007/s13762-019-02576-0

[34] Shirtcliffe N. J., McHale G., Newton M. I., Perry C. C.: Intrinsically superhydrophobic organosilica sol-gel foams. Langmuir, 19, 5626-5631 (2003). https://doi.org/10.1021/la034204f

[35] Luo Z., Jiang J. B., Yao W.: Synthesis of well-defined telechelic trans-1,4-polyisoprene by oxidative cleavage. Chinese Journal of Polymer Science, 34, 359-366 (2016). https://doi.org/10.1007/s10118-016-1746-Z

[36] Menga N., di Mundo R., Carbone G.: Soft blasting of fluorinated polymers: The easy way to superhydrophobicity. Materials and Design, 112, 414-420 (2017). https://doi.org/10.1016/j.matdes.2017.02.074

[37] Li Q., Chen L., Ding J., Zhang J., Li X., Zheng K., Zhang X., Tian X.: Open-cell phenolic carbon foam and electromagnetic interference shielding properties. Carbon, 104, 90-105 (2016).

https://doi.org/10.1016/j.carbon.2016.03.055
[38] Ling J., Zhai W., Feng W., Shen B., Zhang J., Zheng W. G.: Facile preparation of lightweight microcellular polyetherimide/graphene composite foams for electromagnetic interference shielding. ACS Applied Materials and Interfaces, 5, 2677-2684 (2013).

https://doi.org/10.1021/am303289m

[39] Zhang H-B., Yan Q., Zheng W-G., He Z., Yu Z-Z.: Tough graphene-polymer microcellular foams for electromagnetic interference shielding. ACS Applied Materials and Interfaces, 3, 918-924 (2011).

https://doi.org/10.1021/am200021v

[40] Chen Z., Xu C., Ma C., Ren W., Cheng H-M.: Lightweight and flexible graphene foam composites for highperformance electromagnetic interference shielding. Advanced Materials, 25, 1296-1300 (2013).

https://doi.org/10.1002/adma.201204196

[41] Huang H-D., Liu C-Y., Zhou D., Jiang X., Zhong G-J., Yan D-X., Li Z-M.: Cellulose composite aerogel for highly efficient electromagnetic interference shielding. Journal of Materials Chemistry A, 3, 4983-4991 (2015). https://doi.org/10.1039/C4TA05998K

[42] Kuang T., Chang L., Chen F., Sheng Y., Fu D., Peng X.: Facile preparation of lightweight high-strength biodegradable polymer/multi-walled carbon nanotubes nanocomposite foams for electromagnetic interference shielding. Carbon, 105, 305-313 (2016). https://doi.org/10.1016/j.carbon.2016.04.052

[43] Yan D-X., Ren P-G., Pang H., Fu Q., Yang M-B., Li Z-M.: Efficient electromagnetic interference shielding of lightweight graphene/polystyrene composite. Journal of Materials Chemistry, 22, 18772-18774 (2012). https://doi.org/10.1039/C2JM32692B

[44] Li Y-Q., Samad Y-A., Polychronopoulou K., Liao K.: Lightweight and highly conductive aerogel-like carbon from sugarcane with superior mechanical and EMI shielding properties. ACS Sustainable Chemistry and Engineering, 3, 1419-1427 (2015). https://doi.org/10.1021/acssuschemeng.5b00340

[45] Lan C-T., Zou L-H., Pang H., Wang N., Qiu Y-P., Ma Y.: Multi-reflection-enhanced electromagnetic interference shielding performance of conductive nanocomposite coatings on fabrics. Journal of Colloid and Interface Science, 590, 467-475 (2021). https://doi.org/10.1016/j.jcis.2021.01.074 